\title{
Effect of Cyanoacrylate Adhesive on Tissue Healing After Periodontal Surgery
}

\section{S Sadatmansouri', SH Moradi², B Iranpour* (iD 3}

1- Associate Professor, Periodontology Dept, Dental Faculty, Tehran Medical Sciences, Islamic Azad Universi-

ty, Tehran, Iran

2- Denist

3-Assistant Professor, Periodontology Dept, Dental Faculty, Tehran Medical Sciences, Islamic Azad University, Tehran, Iran

\begin{tabular}{l} 
ARTICLE INFO \\
Article History \\
Received: August 2020 \\
Accepted: Oct 2020 \\
ePublished: Nov 2020 \\
\hline Corresponding author: \\
B Iranpour,Assistant \\
Professor, Periodon- \\
tology Dept, Dental \\
Faculty, Tehran Medical \\
Sciences, Islamic Azad \\
University, Tehran, Iran \\
Email: iranpour1391@ \\
gmail.com
\end{tabular}

\begin{abstract}
Background and Aim: Research on reducing the symptoms and discomfort after periodontal surgery is a priority. This study aimed to evaluate the effect of cyanoacrylate adhesive on tissue healing after periodontal surgery.

Materials and Methods: In this split-mouth clinical trial, all patients who needed periodontal pocket removal surgery in two or more sextants were examined after receiving written informed consent. The mouth of each patient was randomly divided into control and case groups. Cyanoacrylate adhesive was used in the case group, and sutures were used in the control group to close the wound. Pain, plaque index of the surgical site, and tissue healing were evaluated in the first week of follow-up. The probing depth in the surgical site was assessed at the second follow-up (6 weeks after surgery). All the parameters were statistically analyzed by Mann-U-Whitney test. Result: In the first week of follow-up, the level of pain was $4.7 \pm 1.34$ in the control group and $4.4 \pm 1.68$ in the case group with no statistically significant difference $(\mathrm{P}=0.2)$. The healing rate was $3.3 \pm 0.53$ in the control group and $2.7 \pm 0.64$ in the case group with no statistically significant difference $(\mathrm{P}=0.3)$. The plaque index in the first week of follow-up was $3.9 \pm 0.82$ in the control group and $3.8 \pm 0.97$ in the case group $(\mathrm{P}=0.2)$. The probing depth in the sixth week of follow-up was $2.5 \pm 0.67$ in the control group and $2.8 \pm 0.6$ in the case group $(\mathrm{P}=0.2)$.

Conclusion: Considering the results, it seems that cyanoacrylate adhesive can be a good alternative to sutures, especially when the patient cannot present for suture removal at the appointed time.
\end{abstract}

Keywords: Cyanoacrylates, Wound Healings, Periodontal Index, Surgery, Sutures

J Res Dent Maxillofac Sci 2020;5(4):13-19 DOI: 10.29252/jrdms.5.4.13

\section{Introduction:}

Considering the extensive use of periodontal flap surgeries, the postoperative healing process seems to be important. Primary healing is preferred due to its high speed, less scarring, and less patient discomfort, ${ }^{(1,2)}$ and suturing is the most common method for achieving this type of healing. ${ }^{(2,3)}$ The suture thread has the highest rate of tissue response. ${ }^{(4)}$

On the other hand, suturing is a time-consuming process, causes tissue trauma, and increases the likelihood of needle stick. ${ }^{(5,6)}$ Suture removal one week after surgery is uncomfortable for the patient, and if absorbable sutures are used, there is a possibility of premature absorption and wound opening. Sutures can cause fistulas and granulomas due to a lack of biocompatibility. In addition, suturing can cause a wide range of problems, including tissue destruction during suturing, the capillary reaction caused by multi-strand sutures, and increased possibility of wound infection. . $^{(7,8)}$

Due to the mentioned problems, the need for an alternative to suturing is well justified. ${ }^{(4)}$ Cyanoacrylate is one of the biomaterials introduced for this purpose. These materials are a good alternative to sutures in extraoral wounds. 
The advantages of these materials include a short time of placement, patient comfort, resistance to infection, hemostatic properties, and no need for suture removal. Numerous studies have been conducted in the field of cyanoacrylate, each with its shortcomings and limitations. Among these limitations, we can mention the small number of samples, short follow-up time, and limited area under study. $(2,5)$ Due to these shortcomings and limitations, the present study aimed to clinically evaluate the effect of cyanoacrylate adhesive on tissue healing after periodontal surgery in patients referring to the Faculty of Dentistry of Islamic Azad University of Medical Sciences, Tehran, Iran, in 2019.

\section{Materials and Methods:}

This split-mouth clinical trial was conducted on patients referring to the periodontics department of the Faculty of Dentistry of Islamic Azad University of Medical Sciences, Tehran, Iran, in the academic year 2018-19. The IRCT code of this study is IRCT20120220009088N2. All patients who needed bilateral periodontal pocket removal surgery as a sextant (1/6) with minimal surgical intervention on the bone were evaluated after receiving written informed consent.

Exclusion criteria:

1. Patients with systemic diseases affecting the healing process.

2. Consumption of drugs that affect the healing process

3. Pregnancy

4. Patient plaque index higher than $20 \%$.

The mouth of each patient was randomly divided into control and case groups. In the case group, cyanoacrylate adhesive (n-butyl \& 2-octyl cyanoacrylate, Glu-Stitch ${ }^{\circledR}$ GluStitch, Delta, BC, Canada) and in the control group sutures (4.0 non-absorbable silk suture, Supa, Tehran, Iran) were used to close the wound (Figures 1 to 3 ). After surgery, a dose of $400 \mathrm{mg}$ gelofen (Dana Pharmaceutical Co., Tabriz, Iran) was prescribed every 8 hours for pain relief. Also, amoxicillin 500 mg (Dr. Abidi Pharmaceutical Laboratory, Iran) was administered every 8 hours for 7 days.

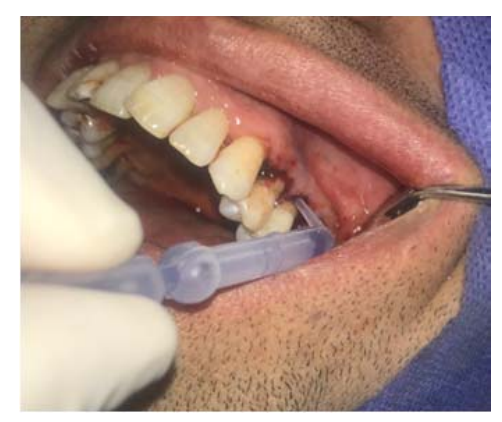

Figure 1. How to use adhesive at the surgical site
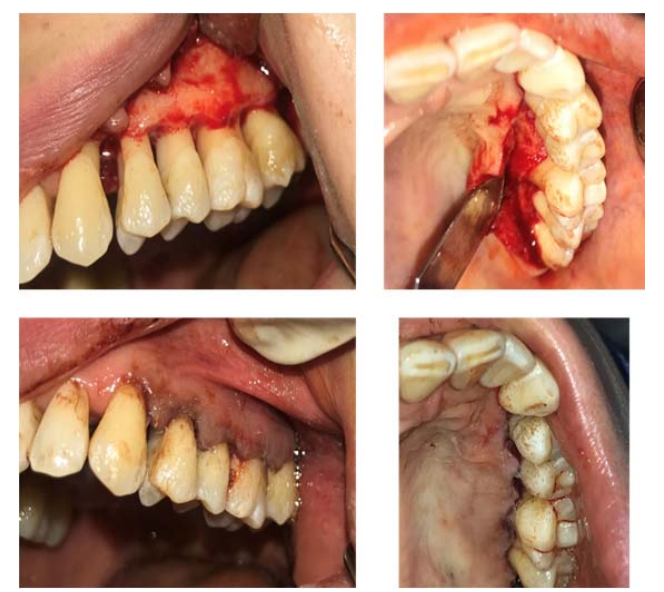

Figure 2. Procedural steps in the case group
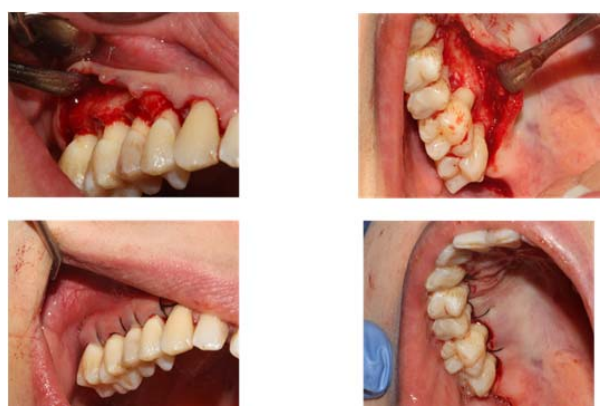

Figure 3. Procedural steps in the control group 
The level of pain was measured by the visual analog scale (VAS). ${ }^{(9)}$ This scale is a ruler that is divided into 10 parts such that the beginning of the ruler (zero) indicates painlessness, and the end of the ruler indicates the maximum pain that a person can imagine. The level of pain was followed-up from the day of surgery, every day for a week, according to the questionnaire given to the patient. The patient was contacted for a reminder. The patient marked the level of pain every day for the first week in the questionnaire according to the VAS ruler and then referred and was evaluated a week later.

The plaque index at the surgical site was evaluated at the time of first follow-up (one week after surgery) with the Turesky-Gilmore-Glickman modification. ${ }^{(10)}$ In this index, no plaque is indicated with 0 . Scattered points of plaque in the cervical region are indicated with 1 . A continuous narrow strip of plaque (less than $1 \mathrm{~mm}$ ) is indicated with 2 . A strip of plaque that is more than one millimeter and surrounds less than onethird of the tooth is marked with 3. A plaque that surrounds at least one-third but less than two-thirds of the tooth is marked with 4 . A plaque that surrounds two-thirds and more of the crown is marked with 5. (10) $^{-}$

The depth of probing at the surgical site was measured at the time of the second follow-up (6 weeks after surgery) with a Williams probe. ${ }^{(11-20)}$

The rate of healing was determined by the Landry index. This index includes five levels, which are divided into some degrees based on tissue color, response to palpation, granulation tissue, and wound edge condition, as follows: ${ }^{(8)}$

Healing index 1 (very poor) includes two or more of these: gingival redness of $50 \%$ or more, bleeding in response to tissue palpation, granulation tissue, nonepithelialized wound edges.

Healing index 2 (poor) includes gingival redness of $50 \%$ or more, bleeding in response to tissue palpation, granulation tissue, non-epithelialized wound edges, and connective tissue exposure.

Healing index 3 (good) includes gingival redness of $25 \%$ or more but less than $50 \%$, no bleeding in response to tissue palpation, no granulation tissue, and no exposure of connective tissue.

Healing index 4 (very good) includes gingival redness less than $25 \%$, no bleeding in response to tissue palpation, no granulation tissue, and no exposure of connective tissue.

Healing index 5 (excellent) includes pinkness of the tissue, no bleeding in response to tissue palpation, no granulation tissue, and no exposure of connective tissue.

Finally, the level of pain, plaque index of the surgical site, probing depth, and rate of healing in that area at the time of follow-up were statistically ana- lyzed by Wilcoxon test.

\section{Results:}

This split-mouth study involved 10 patients. Periodontal surgical specimens included 20 samples that were divided into two therapeutic groups of suturing (without adhesive) and cyanoacrylate adhesive.

The mean age of the subjects was 38.7 years, from a minimum of 31 years to a maximum of 50 years, and included $30 \%$ male ( 3 persons) and $70 \%$ female ( 7 persons). None of the subjects had systemic disease affecting tissue healing. The subjects were not pregnant and did not smoke. The plaque index of all patients before surgery was less than $20 \%$. In the first week of follow-up, the level of pain was $4.7 \pm 1.34$ in the control group and $4.4 \pm 1.68$ in the case group with no statistically significant difference $(\mathrm{P}=0.2)$. The healing rate was $3.3 \pm 0.53$ in the control group and $2.7 \pm 0.64$ in the case group with no statistically significant difference $(\mathrm{P}=0.3)$. The plaque index at the first week of follow-up was $3.9 \pm 0.82$ in the control group and $3.8 \pm 0.97$ in the case group with no statistically significant difference $(\mathrm{P}=0.2)$. The probing depth in the sixth week of follow-up was $2.5 \pm 0.67$ in the control group and $2.8 \pm 0.6$ in the case group with no statistically significant difference $(\mathrm{P}=0.2)$. Table 1 shows the studied parameters in patients in the first week of follow-up. Table 2 shows the studied parameters in patients in the sixth week of follow-up. 
Table 1. Parameters studied in patients in the first week of follow-up

\begin{tabular}{llll}
\hline Parameter/Group & Cyanoacrylate adhesive & Suture & P-Value \\
\hline Pain & $4.4 \pm 1.68$ & $4.7 \pm 1.34$ & $\mathrm{P}=0.2$ \\
\hline Healing & $2.7 \pm 0.64$ & $3.3 \pm 0.53$ & $\mathrm{P}=0.3$ \\
\hline Plaque index of the surgical site & $3.8 \pm 0.97$ & $3.9 \pm 0.82$ & $\mathrm{P}=0.2$ \\
\hline
\end{tabular}

Table 2. Parameters studied in patients in the sixth week of follow-up

\begin{tabular}{llll}
\hline Parameter/Group & Cyanoacrylate adhesive & Suture & P-Value \\
& & & \\
\hline Probing depth & $2.8 \pm 0.6$ & $2.5 \pm 0.67$ & $\mathrm{P}=0.2$ \\
& & & \\
\hline
\end{tabular}

\section{Discussion:}

The aim of this clinical study was to evaluate the effect of cyanoacrylate adhesive on tissue healing after periodontal surgery. The findings of the study showed that the use of cyanoacrylate adhesive compared to sutures did not make a significant difference in terms of pain, healing, plaque index of the surgical site, and probing depth of the area. Considering the positive properties of the adhesive such as a short application time, ${ }^{(21)}$ hemostatic effect, ${ }^{22)}$ anti-inflammatory effect, ${ }^{(7)}$ and antibacterial properties, ${ }^{(23)}$ its use seems appropriate.

Wound healing after surgery can be achieved by carefully aligning the wound edges and protecting the wound from bacterial contamination. Infection and inflammation of the wound lead to a decrease in tissue epithelialization, deceleration of the wound healing process, as well as increased pain and discomfort of the patient. It is necessary to use sutures or tissue adhesives to achieve proper healing of periodontal tissue after surgery. ${ }^{(7)}$

Considering the split-mouth design of this study, there was no significant difference between the two groups in terms of patients' age, related diseases, and diet, but the number of female samples was more than the number of male sam ples, which was similar to the study performed by Stavropoulou et al. ${ }^{(21)}$ According to the study background, this does not seem to affect the results of the research, because in the study by Vastani and Maria, ${ }^{(2)}$ as well as in the study conducted by Kumar et al, ${ }^{(7)}$ the gender of the samples has not been mentioned.

The 10-point VAS questionnaire was completed daily by patients for one week after surgery to assess patients' pain, and finally, the mean level of pain of patients during one week was compared between the two groups, which was not statistically significant. This finding was similar to the findings of the study by Moghareh-Abed and Mirmohammadi. (24) Also, in the study performed by Stavropoulou et al, which examined the use of cyanoacrylate adhesive in donor sites of connective tissue grafts, there was no significant difference between the groups in terms of pain. (21) In the study by Oladega et al, which examined the use of cyanoacrylate adhesive after wisdom tooth extraction surgery, there was no significant difference between the groups in terms of pain. ${ }^{(25)}$ In the study by Khalil et al, no significant difference was reported in terms of pain between the groups, but patients' discomfort and burning were significantly higher in the control group. ${ }^{(26)}$ 
ence of pain is limited, meaning that pain memory is inaccurate and may change due to different environmental conditions. ${ }^{(27)}$ The patient may report more pain depending on the general condition of the body and quality of life or the stresses experienced in one day, and vice versa, if the patient has had a good day, the pain may be less in the questionnaire.

The study by Rewainy et al, which examined the use of cyanoacrylate adhesive to close the mucoperiosteal flap following wisdom tooth extraction surgery, showed reduced pain, better homeostasis, and less localized tissue response. $^{(20)}$

Tissue healing rate was assessed based on the Landry index (an index that includes 5 levels and is divided into 1-5 degrees based on tissue color, response to palpation, granulation tissue, and wound edge condition) on the seventh day after surgery. Based on this index, there was no significant difference between the control and case groups. No similar study was available in the study background to measure tissue healing with this index, but several other studies have measured microscopic and clinical indices of tissue healing. The study by Kumar et al shows a lower rate of infiltration of neutrophils, lymphocytes, histiocytes, and eosinophils. ${ }^{(7)}$

Khurana et al assessed the early healing index and reported that in the first week, the rate of healing was higher in the case group while in the second week after surgery, there was no significant difference between the control and case groups. ${ }^{(4)}$ Kulkarni et al examined the rate of healing and inflammatory indices by preparing a biopsy from the surgical site and concluded that in the first week after surgery, the rate of inflammation was lower in the case group, but 21 days and 6 weeks after surgery, both groups had a similar healing pattern, and it can be concluded that cyanoacrylate tissue adhesive helps early initial healing. ${ }^{(17)}$

Considering the fibrinolytic effect of saliva, it seems that one of the factors affecting the better early initial healing in the area of cyanoacrylate adhesive is the complete coverage of the wound and preventing saliva from contact with the wound. ${ }^{(7)}$
The plaque index of the surgical site was evaluated by the Turesky-Gilmore-Glickman modification, and there was no significant difference in the amount of plaque between the groups, which was the same in the study by Khurana et al. ${ }^{(4)}$ In the study conducted by Abullais et al, in the first week after surgery, the plaque index was lower in the case group than in the control group, but 21 days and 42 days after surgery, no significant difference was observed in the plaque index of the two groups. ${ }^{(28)}$ The results of studies by Kulkarni et al ${ }^{(17)}$ and Giray et al ${ }^{(29)}$ were inconsistent with the present study. In both studies, the rate of plaque index in the surgical site was higher in the control group, which seems to be reasonable since sutures provide a suitable place for the formation of bacterial biofilm. ${ }^{(17,29)}$

The depth of probing in the surgical site was measured in the sixth week after surgery with a periodontal probe. There was no significant difference between the control and case groups in this parameter, which is similar to the study by Khurana et al. ${ }^{(4)}$ In a study by Barbosa et al, the wound at the areas of free gingival grafting was closed with sutures in the control group and with cyanoacrylate adhesive in the case group. ${ }^{(30)} \mathrm{At}$ day 45 and day 90 after the operation, they measured the probing depth and found that the probing depth was not significantly different between the two groups. ${ }^{(30)}$

\section{Conclusion:}

Considering the similarity of the studied indices in the two groups and the advantages of cyanoacrylate adhesive, such as antibacterial and hemostatic properties, no inflammatory effect on the tissue, quick and easy application, and no need for suture removal, it seems that cyanoacrylate adhesive can be a good alternative to sutures, especially when the patient cannot refer for suture removal at the appointed time.

\section{References:}

1.Hollander JE, Singer AJ. Laceration Management. Ann Emerg Med. 1999 Sep;34(3):356-67.

2. Vastani A, Maria A. Healing of intraoral wounds closed using silk sutures and isoamyl 2-cyanoacrylate glue: a comparative clinical and histologic study. J Oral Maxillofac Surg. 2013 Feb;71(2):241-8. 
3.Hollander JE, Singer AJ, Valentine S, Henry MC. Wound Registry: Development and Validation. Ann Emerg Med. 1995;25(5):675-84.

4.Khurana JV, Mali AM, Mali RS, Chaudhari AU. Comparative evaluation of healing after periodontal flap surgery using isoamyl 2-cyanoacrylate (bioadhesive material) and silk sutures: A split-mouth clinical study. J Indian Soc Periodontol. 2016;20(4):417-22.

5.Koonce SL, Eck DL, Shaddix KK, Perdikis G. A prospective randomized controlled trial comparing N-butyl-2 cyanoacrylate (Histoacryl), octyl cyanoacrylate (Dermabond), and subcuticular suture for closure of surgical incisions. Ann Plast Surg. 2015;74(1):107-10.

6.Vinters HV, Galil KA, Lundie MJ, Kaufmann JC. The histotoxicity of cyanoacrylates. A selective review. Neuroradiology. 1985;27(4):279-91. 7.Kumar MS, Natta S, Shankar G, Reddy SH, Visalakshi D, Seshiah GV. Comparison between Silk Sutures and Cyanoacrylate Adhesive in $\mathrm{Hu}-$ man Mucosa- A Clinical and Histological Study. J Int Oral Health. 2013;5(5):95-100.

8. Hemalatha R, Hemagaran G. Effectiveness of Honey and Aloe Vera on Post Extraction Healing. J Dent Med Sci. 2015 May;14(5):123-8.

9. Jung GH, Jung S, Park HJ, Oh HK, Kook MS. Factors Influencing Perception of Facial Attractiveness: Gender and Dental Education. J Craniofac Surg. 2018;29(2):e170-e5.

10.Naik SP, Punathil S, Shetty P, Jayanti I, Jalaluddin M, Avijeeta A. Effectiveness of Different Bristle Designs of Toothbrushes and Periodontal Status among Fixed Orthodontic Patients: A Double-blind Crossover Design. J Contemp Dent Pract. 2018;19(2):150-5.

11.Allen DR, Caffesse RG. Comparison of results following modified Widman flap surgery with and without surgical dressing. J Periodontol. 1983;54(8):470-5.

12. Sagar P, Prasad K, Lalitha RM, Ranganath K. Cyanoacrylate for Intraoral Wound Closure: A Possibility? Int J Biomater. 2015;2015:165428. 13. Samuel PR, Roberts AC, Nigam A. The use of Indermil (n-butyl cyanoacrylate) in otorhinolaryngology and head and neck surgery. A preliminary report on the first 33 patients. J Laryngol Otol. 1997;111(6):536-40.

14. Turkaslan T, Ozcan H, Dayicioglu D, Ozsoy Z. Use of adhesives in cleft palate surgery: a

18 J Res Dent Maxillofac Sci 2020;5(4) new flap fixation technique. J Craniofac Surg. 2005;16(4):719-22.

15. Collins JA, James PM, Levitsky SA, Bredenburg CE, Anderson RW, Leonard F, et al. Cyanoacrylate adhesives as topical hemostatic aids. II. Clinical use in seven combat casualties. Surgery. 1969;65(2):260-3.

16. Heisterkamp CA 3rd, Simmons RL, Vernick J, Matsumoto T. Solid organ injuries in Vietnam. Emergency hemostasis with N-butyl cyanoacrylate adhesive. Arch Surg. 1970 Jan;100(1):10912.

17. Kulkarni S, Dodwad V, Chava V. Healing of periodontal flaps when closed with silk sutures and N-butyl cyanoacrylate: a clinical and histological study. Indian J Dent Res. 2007 AprJun;18(2):72-7.

18. Hupp JR, Ellis E, Tucker MR. Contemporary Oral and Maxillofacial Surgery. St. Louis, Mo: Elsevier, Chicago, 2014:185-200.

19. Newman MG, Takei H, Klokkevold PR, Carranza FA. Carranza's Clinical Periodontology. W.B: Philadelphia, 2015:525-6.

20. Rewainy M, Osman S, El-prince N. The use of n-butyl cyanoacrylate adhesive in the closure of mucoperiosteal flap after the surgical extraction of impacted mandibular third molar. Alexandria Dent J. 2015;40(2):152-159.

21.Stavropoulou C, Atout RN, Brownlee M, Schroth RJ, Kelekis-Cholakis A. A randomized clinical trial of cyanoacrylate tissue adhesives in donor site of connective tissue grafts. J Periodontol. 2019;90(6):608-15.

22. Al-Belasy FA, Amer MZ. Hemostatic effect of n-butyl-2-cyanoacrylate (histoacryl) glue in warfarin-treated patients undergoing oral surgery. J Oral Maxillofac Surg. 2003 Dec;61(12):1405-9. 23.Kaderi MA, Menaka KB, Metgud RM, Gharat MR, Naik PS, Ajbani JM, et al. In-vitro evaluation of antibacterial potential of cyanoacrylate tissue adhesives for intraoral wound closure. J Dent Mater Tech. 2017;6(4):163-9.

24.Moghareh-Abed A, Mirmohammadi SH. Comparison of the use of silk sutures and cyanoacrylate tissue glue after periodontal flaps in patients with moderate periodontitis. J Islam Dent Assoc Iran. 2006 Summer;18(59):44-50. 25.Oladega AA, James O, Adeyemo WL. Cyanoacrylate tissue adhesive or silk suture for closure of surgical wound following removal of an

http://www.jrdms.dentaliau.ac.ir 
impacted mandibular third molar: A randomized controlled study. J Craniomaxillofac Surg. 2019;47(1):93-8.

26.Khalil HS, Elshall MA, Al-Harbi Y, Al-Asmar S, Al-Wadee M. Healing of oral surgical wounds using $3 / 0$ silk suture and nsbutyl cyanoacrylate tissue adhesive. Egypt Dent J. 2009 Oct; 55(4):2607-2613.

27. Breivik H, Borchgrevink PC, Allen SM, Rosseland LA, Romundstad L, Hals EK, et al. Assessment of pain. Br J Anaesth. 2008 Jul;101(1):1724.

28.Abullais A, Chavan A, Dani N, Al-Qahtani N, Al-Qahtani S, Priyanka N. Comparative Evaluation of N Butyl Cyanoacrylate and Silk Sutures on Healing of Periodontal Flaps: A Clinical and Histological Evaluation. Kathmandu Univ Med J. 2018;63(3):253-8.

29. Giray CB, Atasever A, Durgun B, Araz K. Clinical and electron microscope comparison of silk sutures and n-butyl-2-cyanoacrylate in human mucosa. Aust Dent J. 1997 Aug;42(4):255-8. 30. Barbosa FI, Corrêa DS, Zenóbio EG, Costa FO, Shibli JA. Dimensional changes between free gingival grafts fixed with ethyl cyanoacrylate and silk sutures. J Int Acad Periodontol. 2009 Apr;11(2):170-6.

cite this paper as: Sadatmansouri S, Moradi S, iranpour B. Effect of Cyanoacrylate Adhesive on Tissue Healing After Periodontal Surgery. J Res Dent Maxillofac Sci.2020;5(4):13-19 